\title{
Lack of Change in Susceptibility of Pseudomonas aeruginosa in a Pediatric Hospital Despite Marked Changes in Antibiotic Utilization
}

John A. Bosso

To view enhanced content go to www.infectiousdiseases-open.com

Received: March 25, 2014 / Published online: May 15, 2014

(C) The Author(s) 2014. This article is published with open access at Springerlink.com

\section{ABSTRACT}

Introduction: It is assumed that a direct relationship exists between the extent of use of any given antibiotic or antibiotic class and the degree of susceptibility or resistance on the part of various bacteria to that antibiotic or class.

Methods: Pseudomonas aeruginosa susceptibility rates and utilization of key antipseudomonal antibiotics in a pediatric hospital, reflected as grams/1,000 patient days, were studied over a 7-year period.

Results: While the volume of use of a number of antibiotics changed dramatically over this time period, susceptibility of Pseudomonas to these same agents remained relatively stable. The use of aminoglycosides decreased $14.5 \%$ while that of piperacillin/tazobactam increased

Electronic supplementary material The online version of this article (doi:10.1007/s40121-014-0028-8) contains supplementary material, which is available to authorized users.

J. A. Bosso $(\bowtie)$

Department of Clinical Pharmacy and Outcome Sciences, South Carolina College of Pharmacy and Division of Infectious Disease, Medical University of South Carolina College of Medicine, Charleston, SC, USA

e-mail: bossoja@musc.edu
$92 \%$ over the period of observation while susceptibility generally varied by $<10 \%$.

Conclusion: Contrary to popular belief, changes in antibiotic utilization patterns do not always result in changes in susceptibility thus emphasizing the importance of continual institutional monitoring of antibiotic use and susceptibility patterns.

Keywords: Antibiotic utilization; Infectious disease; Pediatrics; Pseudomonas aeruginosa; Susceptibility

\section{INTRODUCTION}

It is assumed that there is a relationship between patterns of use of any given antibiotic or antibiotic class and extent of bacterial resistance to that antibiotic or class. More specifically, it is believed that as the use of an antibiotic increases over time, resistance to that antibiotic on the part of one or more bacteria will also increase as would rates of infections with antibiotic-resistant pathogens. Research in this area has indeed provided examples of such relationships although they are not predictably present [1, 2]. However, when such 
relationships occur, they may well have implications for proactive stewardship initiatives and empiric prescribing decisions. Most, if not all investigations regarding these potential relationships have been performed in adult populations with few, if any, studies focusing in on pediatric drug use/resistance in pediatric hospitals. The purpose of the present study was to explore potential relationships between antipseudomonal antibiotic use and susceptibility of Pseudomonas aeruginosa, a common nosocomial pathogen, to these antibiotics in a pediatric hospital over a 7-year period.

\section{METHODS}

The Medical University of South Carolina Children's Hospital is a 186 bed facility including 50 neonatal specialty beds. Approximately, 4,700 children between the ages of 0 and 17 years are cared for annually. The study was approved by the institution's Institutional Review Board. The analysis in this article is based on existing data, and does not involve any new studies of human or animal subjects performed by any of the authors. Susceptibility data for inpatient-derived $P$. aeruginosa isolates collected between January 1, 2006 and December 31, 2012 were retrieved from hospital microbiology records and antibiotic use data were retrieved from the pharmacy database. The antibiotics of interest were amikacin, cefepime, ciprofloxacin, gentamicin, meropenem, piperacillin/ tazobactam, and tobramycin and all drug use was expressed as grams/1,000 patient days. To have a statistically valid sample of tested isolates $(\geq 30)$, periods of analysis were divided into six quarter increments (e.g., January 2006 through June 2007) and we thereby analyzed a total of six periods within the 7-year time span. Analysis of potentially significant changes in either antibiotic use or susceptibility, over time (period 1 vs. period 4), was performed via paired $t$ test and Chi-square test, respectively. A trend analysis (linear regression) of susceptibility over time was also completed. All statistical analyses were performed using SPSS v.21 (IBM, Armonk, NY, USA).

\section{RESULTS}

Little change was observed in susceptibility of $P$. aeruginosa over the time period of interest with the biggest change being a $12 \%$ difference from period 1 to period 4 for aztreonam (Table 1 ). Conversely, the utilization of most of the antibiotics increased over time with the greatest change observed for piperacillin/ tazobactam (92\% increase), although overall antibiotic utilization change was not statistically significant (Table 1). As a group, utilization of aminoglycosides decreased (14.5\% decrease for the class). Use of both amikacin and gentamicin decreased while that of tobramycin increased. No changes in either susceptibility proportions or antibiotic utilization were statistically significant $(P>0.05)$. Trend analysis of susceptibility over time revealed poor data fits (as reflected by $R^{2}$ ) suggesting no or weak linearity. As susceptibility of $P$. aeruginosa was relatively stable over this time period, tests of correlation or cause-and-effect between antibiotic use over time and susceptibility over time were not pursued.

\section{DISCUSSION}

It is generally assumed that increased use of an antibiotic or antibiotic class within a healthcare environment will result in rising resistance to 


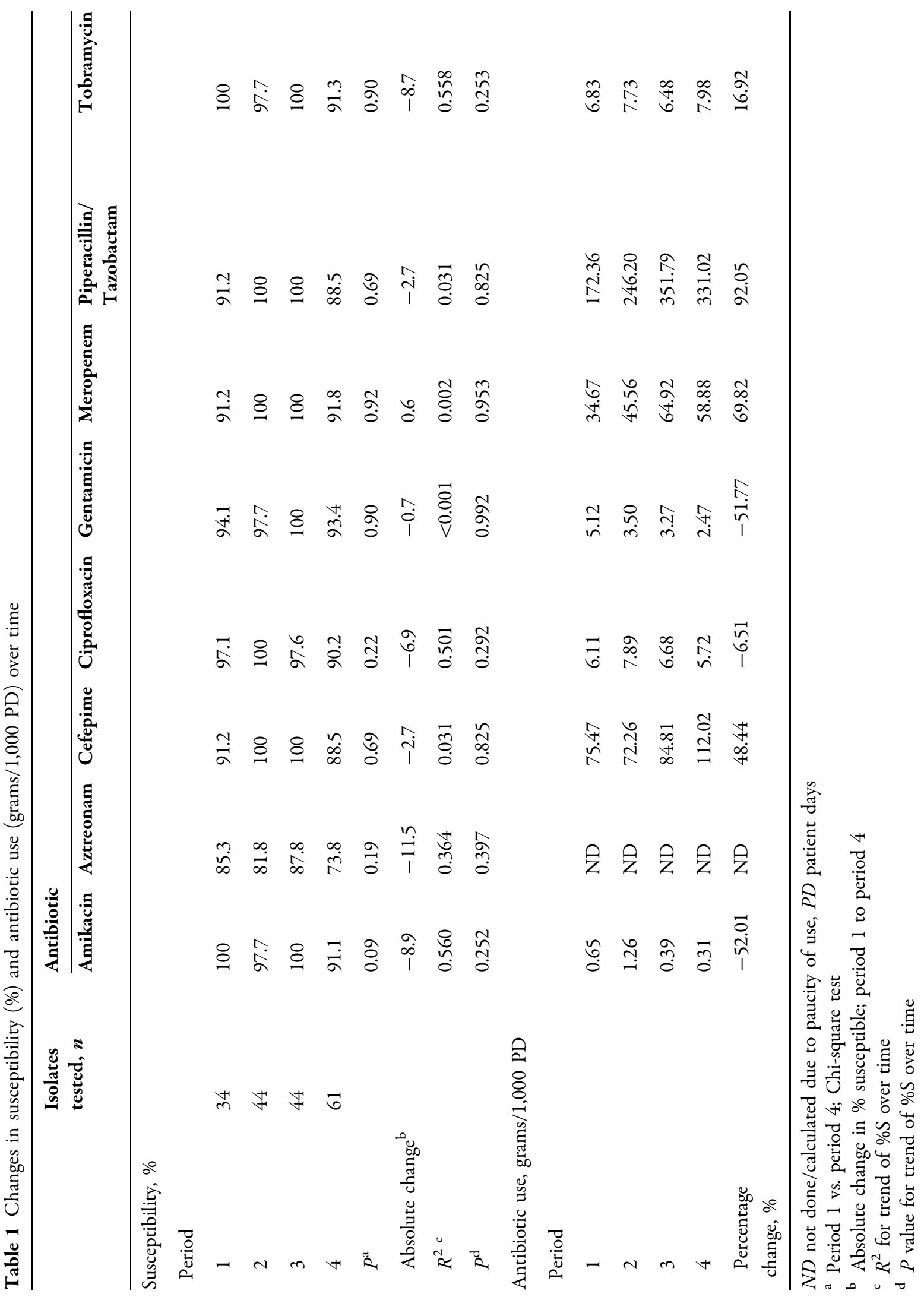


that drug or class. While not always the case, some studies have indeed demonstrated that relationship. By way of example, Plüss-Suard et al. [3] demonstrated a relationship between extent of carbapenem resistance in $P$. aeruginosa and carbapenem use in a study involving 20 acute care hospitals. Due to such experiences, it is not unusual to meet the challenge of rising resistance by decreasing the use of the apparent offending agent or class and encouraging the use of alternatives. Again, there is evidence that this maneuver can be effective. For example, Martin et al. [4] documented a reduction in the rate of ceftazidime-resistant Klebsiella pneumoniae after the removal of ceftazidime and cefotaxime from the hospital formulary. However, this strategy is not always successful, as the relationship between extent of use and extent of resistance does not always exist $[5,6]$ Further, while this strategy may restore susceptibility to a given drug, it may result in rising resistance to other drugs that are used in its stead [7]. In the current analysis, no large changes in susceptibility were detected despite some rather large changes in utilization of individual antibiotics. As examples, susceptibility rates of $P$. aeruginosa to meropenem and piperacillin/tazobactam remained largely unchanged, despite increases in use of 70 and $92 \%$, respectively, over the 7 -year period of observation. Although no apparent cause-and-effect relationships seemed operative, these results might not pertain to other hospitals especially in light of the variation in antibiotic use from one pediatric hospital to the next [8]. The current study must be viewed in light of being a single-center experience with a limited number of tested isolates. All tested isolates were considered and no attempt was made to distinguish those causing infection from those that may have been colonizers. Further, this analysis did not take into account possible effects from changing infection control practices during the period of interest. Lastly, it is also certainly possible that there could be a significant lag time between changes in antibiotic use and changes in resistance rates.

Regardless of these results, it is important that susceptibility rates be diligently monitored in the current age of rapidly rising antibiotic resistance, including in pediatric settings so that emergent resistant problems can be detected and addressed [9]. Results from a fairly recent survey of hospitals caring for pediatric patients were used to construct a national antibiogram for the years 2010 and 2011 [10]. With the exceptions of aztreonam and gentamicin, reported susceptibility rates for isolates of $P$. aeruginosa in that report were similar to those in our last period of observation. While such national averages may be helpful in settings where a local antibiogram cannot be prepared, local antibiograms are nonetheless the best resource in guiding empiric prescribing decisions.

\section{CONCLUSION}

In summary, the susceptibility of pediatric isolates of $P$. aeruginosa to a number of antibiotics remained relatively stable over a 7-year period despite major changes in utilization of several of these drugs. Thus, large increases in utilization of at least some antibiotics are not uniformly associated with subsequent changes in bacterial resistance.

\section{ACKNOWLEDGMENTS}

No funding or sponsorship was received for this study or publication of this article. The author thanks Carrie Alderman, PharmD for her 
assistance in the collection and organization of data for this analysis. The named author meets the ICMJE criteria for authorship for this manuscript, takes responsibility for the integrity of the work as a whole, and has given final approval for the version to be published.

Conflict of interest. John Bosso declares that he has no conflicts of interest.

Compliance with ethics guidelines. The study was approved by the institution's Institutional Review Board. The analysis in this article is based on existing data and does not involve any new studies of human or animal subjects performed by any of the authors.

Open Access. This article is distributed under the terms of the Creative Commons Attribution Noncommercial License which permits any noncommercial use, distribution, and reproduction in any medium, provided the original author(s) and the source are credited.

\section{REFERENCES}

1. Bosso JA. The impact of antibiotic management on resistance. Pharmacotherapy. 2004;24:224S-31S.

2. Mauldin PD, Salgado CD, Durkalski VL, Bosso JA. Nosocomial infections due to Methicillin-resistant S. aureus and Vancomycin-resistant Enterococcus: relationships with antibiotic use and cost drivers. Ann Pharmacother. 2008;42:317-26.

3. Plüss-Suard C, Pannatier A, Kronenberg A, Mühlemann K, Zanetti G. Impact of antibiotic use on carbapenem resistance in Pseudomonas aeruginosa: is there a role for antibiotic diversity? Antimicrob Agents Chemother. 2013;57:1709-13.

4. Martin C, Ofotokun I, Rapp R, et al. Results of an antimicrobial control program at a university hospital. Am J Health Syst Pharm. 2005;62:732-8.

5. Mohr JF, Jones A, Ostrosky-Zeichner L, Wanger A, Tillotson G. Associations between antibiotic use and changes in susceptibility patterns of Pseudomonas aeruginosa in a private, universityaffiliated teaching hospital: an 8-year-experience: 1995-2002. Int J Antimicrob Agents. 2004;24:346-51.

6. Cook PP, Catrou PG, Christie JD, Young PD, Polk RE. Reduction in broad-spectrum antimicrobial use associated with no improvement in hospital antibiogram. J Antimicrob Chemother. 2004;53:853-9.

7. Rahal JJ, Urban C, Horn D, et al. Class restriction of cephalosporin use to control total cephalosporin resistance in nosocomial Klebsiella. JAMA. 1998;280:1233-7.

8. Gerber JS, Newland JG, Coffin SE, et al. Variability in antibiotic use at children's hospitals. Pediatrics. 2010;126:1067-73.

9. Shlaes DM, Gerding DN, John JF Jr, et al. Society for Healthcare Epidemiology of America and Infectious Diseases Society of America Joint Committee on the prevention of antimicrobial resistance: guideines for the prevention of antimicrobial resistance in hospitals. Clin Infect Dis. 1997;25:584-99.

10. Tamma PD, Robinson GL, Gerber JS, Newland JG, DeLisle CM, Zaoutis TE, Milstone AM. Pediatric antimicrobial susceptibility trends across the United States. Infect Control Hosp Epidemiol. 2013;34:1244-51. 